\title{
Investigation of the Number of Root Canals in Mandibular Molars and Premolars Teeth in Ilam in 2020
}

\author{
Khadijeh Abdal $^{1}$ iD , Parisa Bakhtizad ${ }^{1}$, Amin Kheiri ${ }^{*}$ (iD \\ ${ }^{1}$ Dept of Oral and Maxillofacial pathology, Faculty of Dentistry, Ilam University of Medical Sciences. Ilam, Iran \\ ${ }^{2}$ Dept of Endodontics, Faculty of Dentistry, Ilam University of Medical Sciences. Ilam, Iran
}

Article Info A B S T R A C T

\section{Article type:}

Research article

\section{Article History:}

Received: 07 November 2021

Revised: 25 November 2021

Accepted: 29 August 2021

\section{* Correspondence to:}

Amin Kheiri

Dept of Endodontics, Faculty of Dentistry, Ilam University of Medical Sciences. Ilam, Iran Email: kheiri-a@medilam.ac.ir
Introduction: Teeth may need root canal treatment for various reasons. The anatomy of the root canal varies not only between different types of teeth but also between similar teeth. Although there must be at least one canal in the root, some roots have multiple canal of different length. The goal of this study was investigation of the number of root canals in mandibular molars and premolars teeth in Ilam in 2020.

Material \& Methods: This study was descriptive-analytic study that performed on 60 mandibular premolars and molars (first premolars 15, second premolars 15 , first molars 15 , second molars 15 ) randomly with considering of the sex of patients. Data were analyzed by SPSS22.

(Ethic code: IR.MEDILAM.REC.1399.064)

Findings: In the first and second premolars, the highest frequency of single canal as $86.7 \%$ and $93.3 \%$, respectively. In the first and second molars, the highest frequencies related to the three channels were $53.3 \%$ and $86.7 \%$, respectively. The prevalence of 4-channel molars was higher in women and 3-channel in men. This difference was not statistically significant. Between two radiologists and endodontists to determine the number of root canals in the first and second premolars and the first and second molars, a good agreement was reported with kappa agreement coefficient of 0.92 and $(\mathrm{P}=0.000)$.

Discussion \& Conclusion: According to the results of the present study, the first and second mandibular premolars had mostly single root and one canal, and the first and second mandibular molars had often two roots and three channels.

Keywords: Mandible, Molars, Premolars, Root canals

$>$ How to cite this paper

Abdal KH, Bakhtizad P, Kheiri A. Investigation of the Number of Root Canals in Mandibular Molars and Premolars Teeth in Ilam in 2020. Journal of Ilam University of Medical Sciences. 2022;29(5): 56-62. 


\title{
بررسى تعداد كانال هاى ريشه در دندان هاى مولر و بره مولر منديبل درشهرايلام در

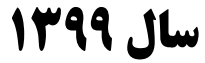

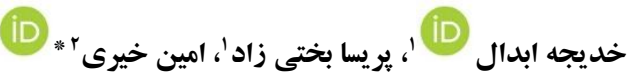

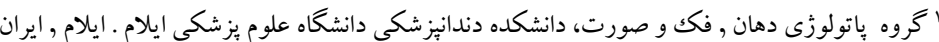

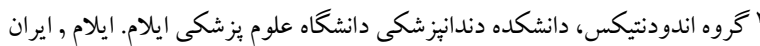 \\ جكيده \\ اطلاعات مقاله - اله
}

مقدمه: دندانها به دلايل مختلفى , نياز به درمان ريشه دارند .آناتومى كانال ريشه ى دندان , نه تنها بين انواع دندانها بلكه نوع مقاله: يُزوهشى

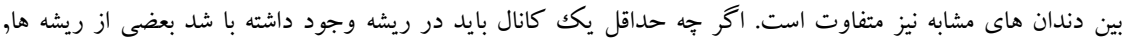

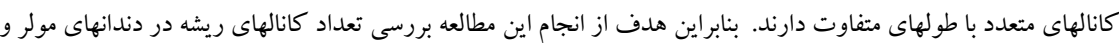

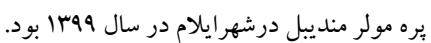

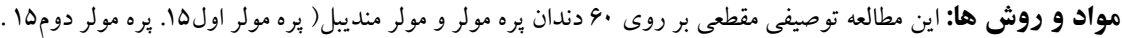

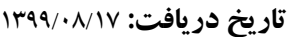

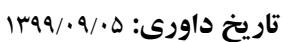

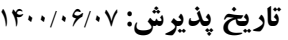

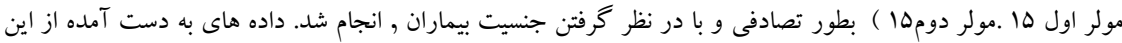

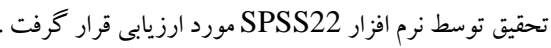

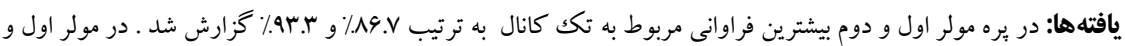

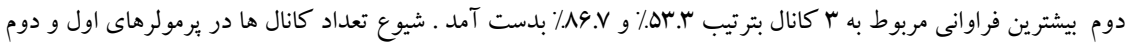

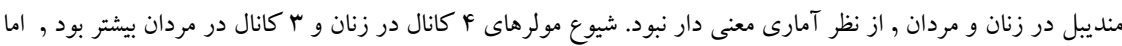

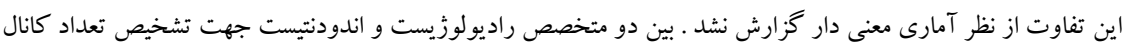

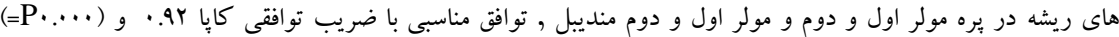
كزارش شد.

نويسنده مسئول: امين خيرى

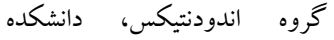
دندانيز شكى دانشكاه علوم يزشكى ايلام. ايلام , ايران

Email: kheiri-

a@medilam.ac.ir

بحث و نتيجه كيرى: بر اساس نتايج مطالعه حاضر ، يره مولر هاى اول و دوم منديبل اكثرا تكك ريشه بودند و يكك كانال داشتند و مولر هاى اول و دوم مندييل نيز در اغلب موارد دو ريشه بودند و سه كانال داشتند . تعداد ريشه و كانال بين مرد و

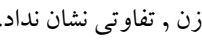


كانال ها در بعضى از دندانها موجب درمان ناقص و اشتباه

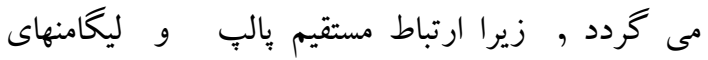

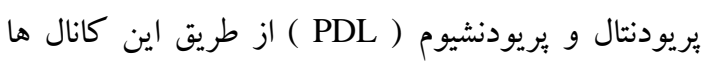

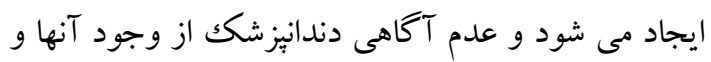

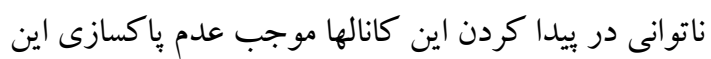
كانالها شده , در نتيجه اين كانال ها مسيرى برائ كائ انتشار

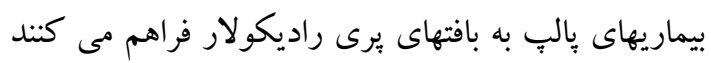

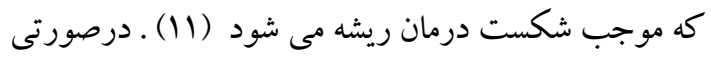
كه اكر دندانْيز شكك بيش از درمان ريشه, آكاهى كاملى از مورفولوزى كانال داشته باشد مى تواند راحت تر تصميم

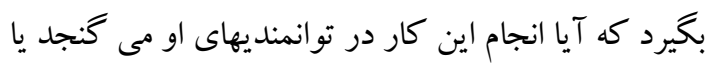
خير و در صورت عدم توانايى در انجام درمان ريشه بيمار

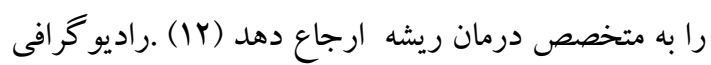

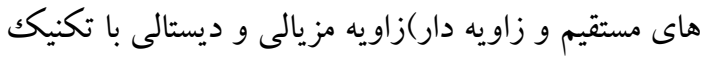

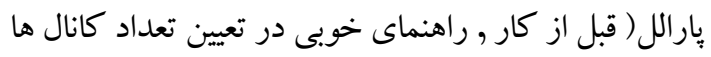
مى باشد . به طور كلى در دندانهاى بره مولر مندييل با بام كانال , نيمه ى سرويكالى ريشه نسبت به حالت معمول

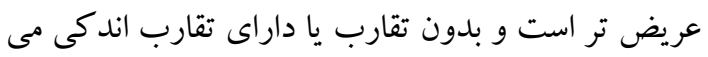

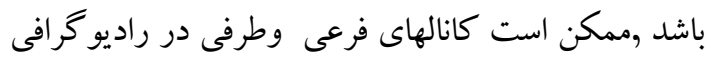

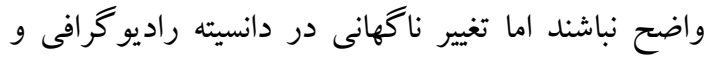

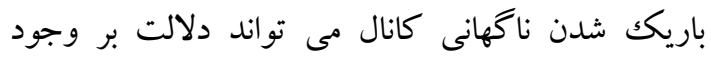
كانالهاى ديخر داشته باشد( ساو (IF).

بررسى تنوعات آناتوميكى كانال از جمله وجود بيش بان

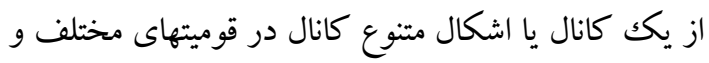
مناطق جغرافيايى مختلف نتايج كاملا متفاوتى را به دنبال داشته است و مطالعات فراوانى در جمعيتهاى مختلف ارايه

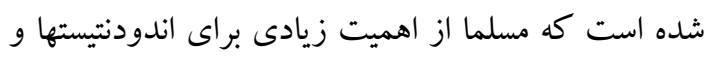
دندانيزشكان عمومى كه خواهان انجام درمان ريشه هستند

$$
\text { برخوردار است (هار). }
$$

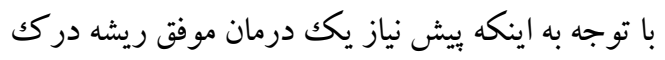

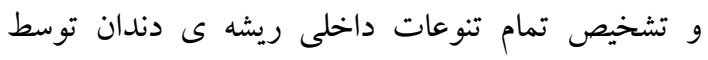
كلينيسن مى باشد , نياز است مطالعات بررسى شيوع كات كانال هاى ريشه در هر منطقه ى جغرافيايى انجام گردد و و از
دندانها به دلايل مختلفى , نياز به درمان ريشه دارند

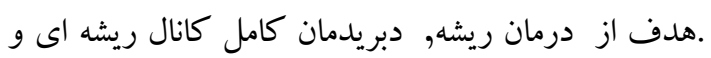
حذف كامل ميكروار گانيسمها و محصولات جانبى درب آنها از

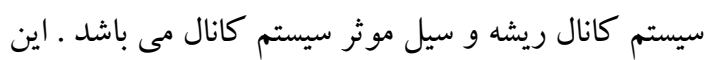

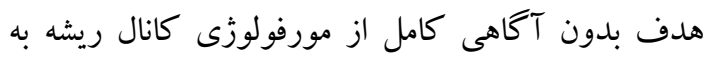

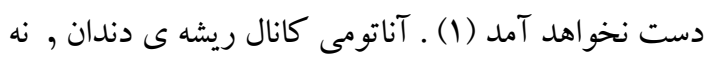
تنها بين انواع دندانها بلكه بين دندانهاى مشابه نيز متفاوت است .اكر جهه انتظار مى رود كه حداقل يكك كانال در ريشه دئه

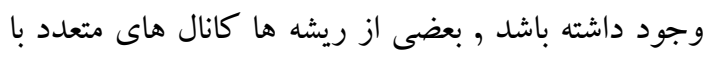
طول هاى مختلف دارند (זوץ)) . درك و و تشخيص تمام جنبه هاى آناتومى كانال ريشه, ويش نيش نياز درمان كانال ريشه مى باشد. درمان موفق ريشه , نيازمند شناخت دقيق آناتومى

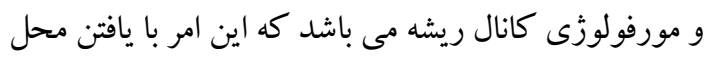
دقيق كانال ها , شكل دهى و پِاكسازى آنها و در نهايت

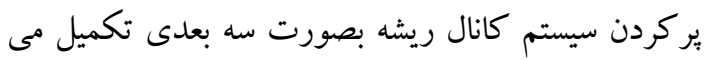

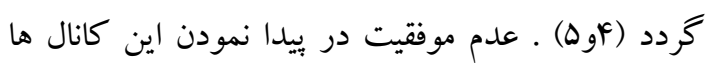
ممكن است باعث شكست درمان و احتمالا بروز درد و

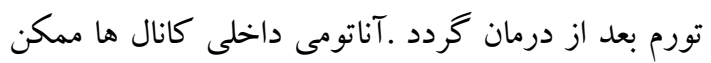

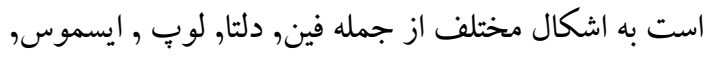
كانال هاى فرعى ولترال , ديده شود كه كار با پسازى و و شكل دهى را سخت و بيجيجيده و با اشكال مو اجه مى سازد

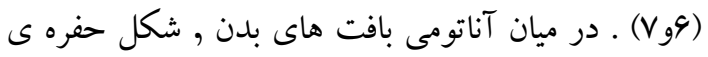
بالٍ دندان از يِيجِيده ترين بخش ها مى باشد. در زمان

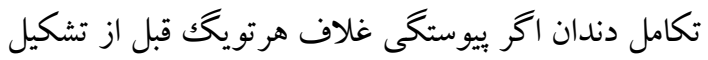

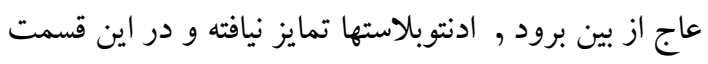
عاج تشكيل نمى شود و موجب تشكيل كانال هاى فرعى و

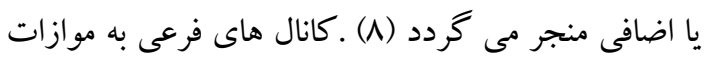

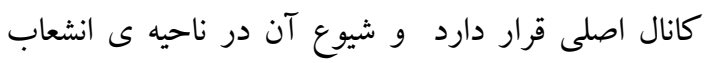

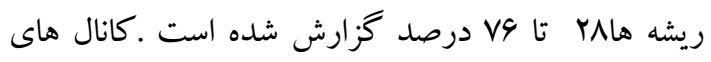

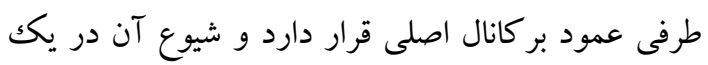

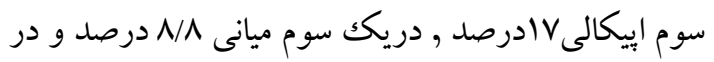

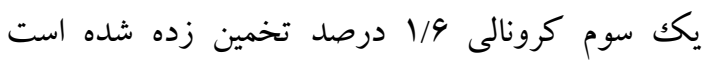

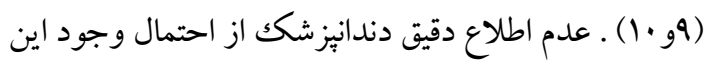


جهت ورود به ميناى دندان از سطح (N SK panaair FX) اكلوزال دندان اقدام به تهيه ى حفره دسترسى كرده و بعد از اينكه حفره ى دسترسى مورد قبول تهيه شد ،با استفاده از فايلهاى دستى Mani - زاين شماره ·.وها (كانالها را بيدا كرده و يس از قرار دادن فايلها در دندان

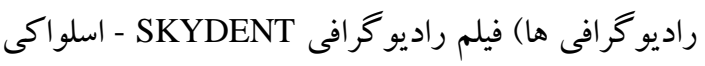
( در نماى مزيو ديستالى و باكو لينگوالى براى هر دندان(توسط دستخاه راديولوزى Planmeca مدل Prox كشور فنلاند( در يكك وسيله ى ثابت كننده به طورى كه موقعيت تيوب و دندان در هر اكسيوز ثابت باشد، انجام شد. با شرايط ولتاز: . KVP4 ,جريان MAN , و زمان اكسيوز ^•••• راديو گرافى با تكنيك موازى به عمل آمد

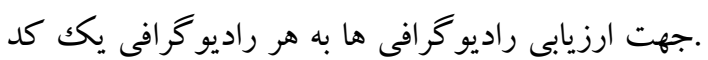
داده و يكك متخصص راديولوزى فك , دهان و صورت و و يكك متخصص درمان ريشه به عنوان مشاهده گر , تصاوير را با هم در يكك جلسه بررسى كرده و نظرات خود را اعلام نمودند. با توجه به وجود اختلاف نظر در بين دو متخصص از ضريب اطمينان استفاده كرديم · براى تحليل داده ها از ضريب توافقى كايا استفاده كرديم و سطح معنى دارىه •. •در نظر كرفته شد. داده هاى به دست آمده از اين مطالعه توسط Spss نسخه بrو سطح معنى دارىه .. · مورد ارزيابى قرار گرفت.

يافته ها يافته هاى حاصل از اين تحقيق نشان داد كه كليه دندان هاى بره مولر اول و دوم در جمعيت زنان و مردان تكك ريشه بودند. شيوع مولر اول r ريشه در مردان ..1 درصد و در زنان الهAدرصد و مولر اول F ريشه در مردان · و در زنان يكك مورد گز ارش شد كه اين تفاوت از نظر امارى معنادار نبود (ه) • P>). در يره مولر اول و دوم بيشترين فراوانى مربوط به تكك كانال به ترتيب A9.V

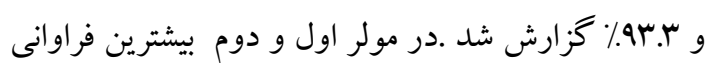

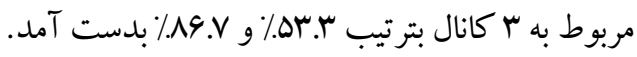
شيوع تعداد كانال ها در برمولرهاى اول منديبل در جمعيت مردان به ترتيب تكك كانال ND.V، دو كانال س. IF.
آنجايى كه دندانهاى منديبل به دليل تنوع در آناتومى داخلى , كانالهاى جانبى و دلتاهاى اييكال جزو مشكلترين دندانها جهت درمان اندو مى باشند, (19) لذا هدف از انجام اين تحقيق , بررسى تعداد كانالها در ريشه ى دندانهاى مولر و يره مولر منديبل در شهر ايلام در سال 9هسا بود كه تا كنون انجام نشده بود .

\section{مواد و روش ها}

اين مطالعه از نوع توصيفى_مقطعى است كه بر روى 9 دندان بيره مولر و مولر منديبل) بيره مولر اول منديبلها،يره مولر دوم منديبلها، مولر اول منديبلها، ,

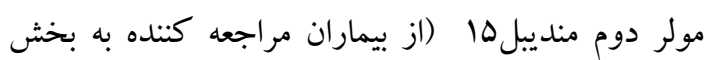
جراحى دانشكده دندانيزشكى ايلام و درمانگاههاى سطح شهر انجام شد. انتخاب نمونه ها , بطور تصادفى و بادر نظر كرفتن فاكتور جنسيت انجام كرفت . معيارهاى ورود به اين مطالعه شامل جمع آورى دندان هايى بود كه متعلق به افراد با اصالت ايلامى باشد ( مسافر و دانشجوى غير بومى نباشد ) . دندانهايى كه ريشه كلسيفيه داشتند از مطالعه خارج شدند.

\section{روش انجام كار}

بعد از جمع آورى نمونه ها ( دندانهاى كشيده شده ) , تمامى بقاياى بافتى و جرم يوشاننده سطح ريشه از دندانها جدا شد. دندانها در درون محلول سديم هييو كلريتهابـه درصد Hypo-Endox)شركت - Mوليدى Morvabon) تهران ( ) و سبس در محلول نرمال سالين pidgin)

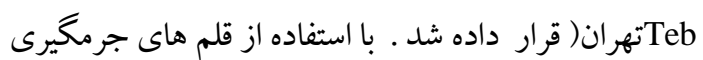
شركت كوشا فرين درمان( جرمهاى موجود در سطح دندان برداشته شد، سيس با استفاده از مشاهده ى بصرى, تعداد ريشه دندان را مورد بررسى قرار داديم. در مرحله ى بعد دندانها در بلو كك كِّى مانت شد و به

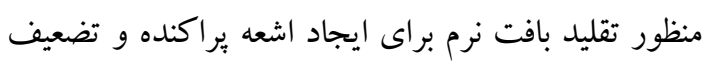

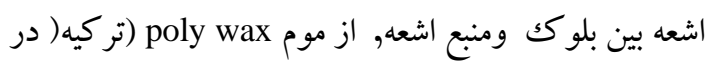
إيكس دندانها استفاده شد , سيس با استفاده از فرز فيشور الماسى (Teeskavan - كرج) و هندييس با سرعت بالا 


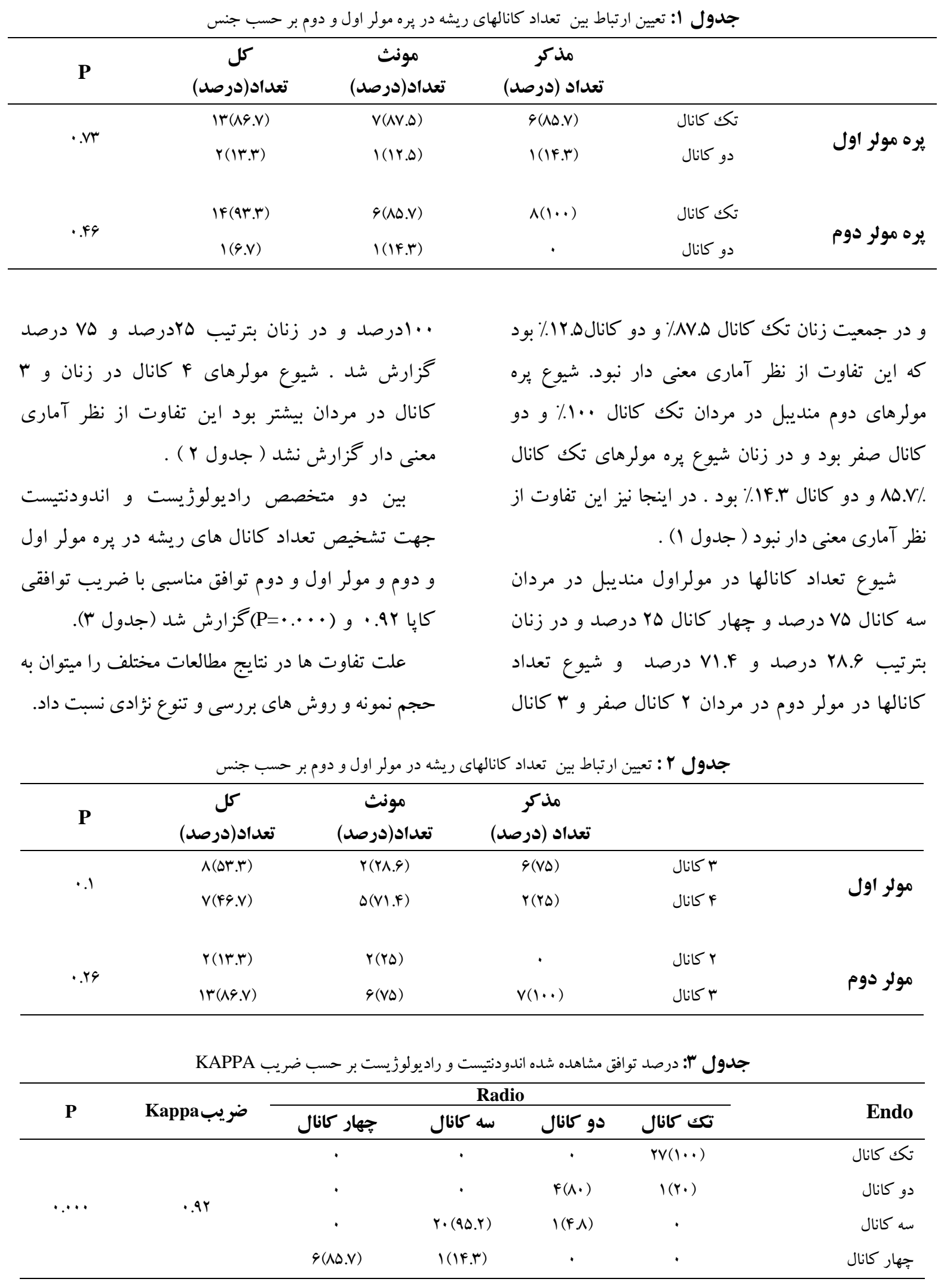

كانال هاى اضافه، كانال هاى جانبى و دلتاهاى إيكال ,

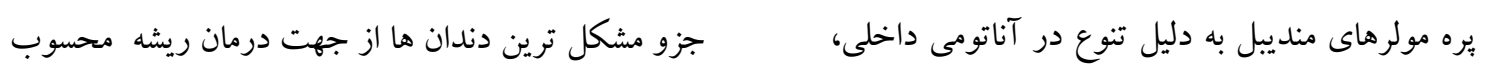


طبق مطالعه ى محمدزاده ى اخلاقى و همكاران , 99.V\% دندانها ى مولر اول دوريشه بودند كه با يافته هاى تحقيق حاضر كه بيش از سهء٪ از دندانهاى مولر اول رادو ريشه نشان دادبيش از •9٪\% موارد , تكك ريشه هستند كه با يافته هاى مطالعه ما همسو است (سY,YY, (YF) . در اينجا عدم شيوع كمتر يرمولرهاى ب كانال را نسبت به مطالعات

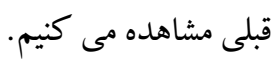
در اين تحقيق شيوع تعداد ريشه و كانال بر اساس جنسيت هم مورد ارزيابى قرار كرفت و نتايج نشان داد

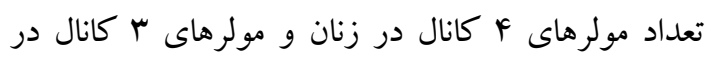
مردان بيشتر است اما از نظر آمارى معنادار نبود ـ. طبق

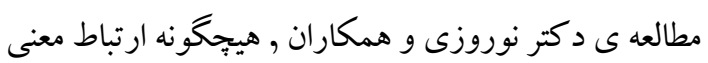
دارى بين تعداد ريشه و جنسيت مشاهده نشد كه با نتايج مطالعه ى حاضر هم سو ميباشد(Yه). ييش بينى مى شود كه نتايج اين مطالعه موجب افزايش دانش كلنيسينها در مورد تنوع تعداد كانالهاى ريشه مى كردد كه در نتيجه ى آن عدم نياز به تكرار درمان و درمانهاى كمكى , صرفه جويى در وقت و هزينه , رضايت بيمار و راحتى دندانيزشك را در يى خواهد داشت و و همجينين بيش آكهى درمان را بهبود مى بخشد.

\section{تشكر و قدردانى}

اين مقاله منتج از يايان نامه دكتراى عمومى دندانيزشكى با كد اخلاق IR.MEDILAM.REC.1399.064 مى باشد. بدين وسيله از دانشخاه علوم يزشكى ايلام كه ما را در انجام اين مطالعه حمايت كردند , كمال تقدير و تشكر را داريم.

تعارض منافع نويسند كان اعلام مى كنند كه تضاد منافعى در اين

مطالعه وجود ندارد.

كد اخلاق: IR.MEDILAM.REC.1399.064

\section{References}

1. Weine FS. Endodontic therapy $.5^{\text {th }}$ ed. Louis CV Mosby Co Publication. 2015; P.123-46.
مى شود (9) . به صورت كلى در دندان هاى منديبل با سه كانال، نيمه سرويكالى ريشه نسبت به حالت معمول عريض تر است و بدون تقارب يا داراى تقارب اندكى ميباشد . ممكن است كانال ها در راديوگر افى واضح نباشند . تغيير ناخهانى در دانسيته راديوگرافى و باريك شدن ناخهانى كانال مى تواند دلالت بر وجود كانال هاى اضافه داشته باشد (مو 11) .در مطالعه ى حاضر اكثريت مولرهاى اول سكاناله هستند كه با مطالعه ى هاشمى نيا و همكاران و مطالعهChourasia و همكاران همسو مى باشد (fاوها). در مقاله ى هاشمى نيا و همكاران , مولر هاى دوم در بيشتر موارد , سه كاناله بودند كه با يافته هاى حاصل از مطالعه حاضر مشابهت دارد (If). در اين مطالعه , تمام يرمولرهاى اول منديبل تكك مكارد ريشه بودند كه با مطالعه Shrestha و همكاران و مطالعه Plaine وب ريشه گزارش نشد (9) IV), در حالى كه در مطالعه دندان هاى بره مولر اول دو ريشه بودند

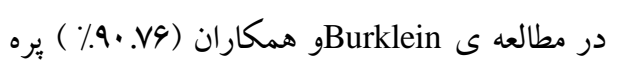
مولر هاى اول تكك ريشه و (14.19٪\% ) بره مولر هاى دوم نيز تكك ريشه بودند (1) . مطالعه حاضر با مطالعه زارع

$$
\text { جهرمى و همكاران همسو نيست (19). }
$$
طبق مطالعه ى رحيمى و همكاران , 91٪ دندان يره مولر اول منديبل , تكك ريشه هستند كه با نتايج مطالعه ى مط مئى حاضر همسو ميباشد , اما در دندانهاى بره مولر دوم منديبل تنوع تعداد ريشه وجود داشت كه با مطالعه ى حاضر همسو

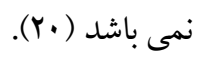
طبق مطالعهChourasia و همكاران , •^^٪ دندان بره مولر اول , تكك ريشه و مابقى دو و سه ريشه بودند كه با مطالعه ى حاضر هم سو نمى باشد (ها). نتايج مطالعات Dou و , Shrestha نشان داد كه بيث لهم لهم از 94\% از بره مولر اول , تكك ريشه هستند كه با نتايج تحقيق حاضر هم سو مى باشد( آو 19) .

2. Enone LL, OyaperoA. Preliminary assessment of endodontic difficulty encountered at a tertiary health 
center in lagos Nigeria. J Int Oral Health. 2018;10:303-10. doi.10.4103/jioh.jioh_200_18

3. Arora R, Gupta T, Mirdha N, Omer M. A case report on aberrant root canal morphology of mandibular first premolar. Dental Sci 2019 ؛ 5:1-17.

4. Anaraki M, Jafarzadeh H, Zarrabi M. Root canal therapy of first and second mandibular premolars with three root canals. J Mash Dent Sch2016!40:187-92. doi.10.7508/iej.2016.02.012

5. Baroudi K, Kazkaz M, Sakas S, Tarakji B. Morphology of root canals in lower human premolars. Niger Med J 2012؛ 53:206-9. doi.10.4103/0300-1652.107554

6. Fathi Z, Rahimi S, Tavakoli R, Amini M. A three rooted mandibular second premolar a case report. $\mathrm{J}$ Dent Res Dent Clin Dent Pros2014; 8: 184-6. doi.10.5681/joddd.2014.034

7. Paul B, Dube K. Endodontic treatment of a mandibular second premolar with three roots and three canals. Case Rep Dent 2014; 20: 97-102. doi.10.1155/2014/973410.

8. KakkarP, Singh A. Mandibular first premolar with three root a case report. Iranian Endod J 2012; 7:207-210.

9. Shehadat S. Cone beam computed tomography of mandibular first permanent molar in a Middle East population. J Int Soc Preve Commun Dentistr2019; 9:458-63. doi.10.4103/jispcd.JISPCD_41_19

10. Saber AM, Altoukhi DH. Consequense of early extraction of compromised first permanent Molar. BMC Oral Health2018ः3:18:59. doi.10.1186/ s12903-018-0516-4

11. Chourasia HR, Boreak N, Tarrosh MY, Mashyakhy M. Root canal morphology of mandibular first premolars in Saudi Arabian southern region subpopulation. Saudi Endod J2017; 7:77-81. doi.10.4103/1658-5984.205130

12. Bhardwaj A, Kottoor J, Albequerque DV, Velmurugan N. Morphologic variation in mandibular premolars a report of three cases. J Con Dent Pract2015; 16:243-7. doi. 10.5005/jp-journals10024-1593

13. Poorni S, Karumaran CS, Indira R. Mandibular first premolar with two root and three canals. Aust Endod J2010؛ 36:32-34. doi.10.1111/j.17474477.2009.00170.x

14. Hasheminia SM, Asjhartabar H. An invitro evaluation of morphologic variation in mandibular first and second molars. Shiraz Uni Dent J2009؛ 10:60-5.

15. Chourasia H, Ganesh K, Meshram, Root canal morphology of mandibular first permanent molars in an Indian population. Int J Dentistr2012; 21:7481. doi.10.1155/2012/745152

16. Shrestha R, SriiR. Diversity of root canal morphology in mandibular first premolar. Kathmandu Uni Med J 2020; 11:66-71.

17. Blaine $\mathrm{M}$. William $\mathrm{H}$. The root and root canal morphology of the human mandibular second premolar a literature review. J Endod2007; 33:5460. doi.10.1016/j.joen.2007.03.020

18. Burklein S, Heck R, Schafer E. Evaluation of the root canal anatomy of maxillary and mandibular premolars in a selected German population using cone beam computed tomographic data. J Endod 2017; 43:1448-52. doi.10.1016/j.joen.2017.03.044

19. Zarejahromi M, Jafari F, Sarami M. Root and canal morphology of mandibular second molar in an Iranian population by clearing method. Shiraz Uni Med Sci2013; 14:78-81.

20. Rahimi S, Shahi S, Yavari HR, Manafi H, Eskandarzadeh N. Root canal configuration of mandibular first and second premolars in an Iranian population. J Dent Res Dent Pros2007; 1:59-64.

21. Dou L, Li D, XuT, TangY, Yang D. Root anatomy and canal morphology of mandibular first premolars in a Chinese population. Sci Rep2017; 7:21-28.

22. Mohammadzadehakhlaghi N, Khalilak Z. Root canal anatomy and morphology of mandibular first molar in selected Iranian population an invitrostudy. Iranian EndodJ 2017; 12:87-91. doi.10.22037/iej.2017.18

23. Singh S, Pawar M. Root canal morphology of South Asian Indian mandibular premolar teeth. J Endod 2014; 40:1338-41. doi.10.1016/j.joen.2014.03.021

24. Islam MA, Wakia $\mathrm{T}$, Alam MS. Root canal morphology of mandibular first premolars of Bangladeshi population. Update Dent Coll J 2013; 2:3-7.

25. Norouzi N, Kavousi A, Moosazade M, Esahmi E. [Investigation root canal number and morphology of mandibular anterior teeth using cone beam computed tomography]. J Mazandaran Uni Med Sci 020; 29:119-23. (Persian) 